\title{
Impact of route of delivery upon regulators of adipose tissue lipid metabolism in the pig
}

\author{
A. Thickitt ${ }^{1}$, P. Fainberg ${ }^{1}$, L. Clarke ${ }^{2}$, P. R. Kemp ${ }^{3}$, M. Hyde ${ }^{4}$ and A. Mostyn ${ }^{1}$ \\ ${ }^{1}$ School of Veterinary Medicine and Science, University of Nottingham, Sutton Bonington Campus, Leicestershire \\ LE12 5RD, UK, ${ }^{2}$ Section of Comparative Medicine, ${ }^{3}$ Section of Molecular Medicine and ${ }^{4}$ Section of Neonatal Medicine, \\ Imperial College London, London SW10 9NH, UK
}

\begin{abstract}
Vaginal delivery (VD) is associated with a plethora of physiological adaptations essential for survival of the newborn outside the womb ${ }^{(1)}$. Pre-labour caesarean section (CS) may reduce, or abolish, some of these normal adaptatory responses, leading to an impaired adaptation to extrauterine life. In addition to these short-term effects, CS may promote longer term programming of certain organs and tissues, evidence from Hyde et al. have demonstrated that neonatal offspring delivered by VD have hepatic steatosis and alterations in key genes which regulate lipid ${ }^{(2,3)}$. It is unknown whether lipid is stored in the liver in these animals at the expense of normal adipose tissue (AT) storage. The aim of this study was to investigate the impact of CS on regulators of AT lipid metabolism in the neonatal pig.

Sows were randomly allocated to the CS or VD group, routine CS was carried out on day 112 (porcine gestation $114 \mathrm{~d}$ ), after which sows were humanely euthanised by intravenous injection of sodium pentobarbital. VD sows gave birth normally without intervention. Piglets were dried, given oxygen and vitamin $\mathrm{K}$ intramuscularly then provided with $100 \mathrm{ml}$ of milk replacer and ad libitum water in separate bowls every $4 \mathrm{~h}$. On day 7 all piglets were euthanised as described above and AT was removed and stored at $-80^{\circ} \mathrm{C}$ until laboratory analysis. Eleven piglets were used in this study, six VD and five delivered by CS. Real-time PCR with optimised porcine primers was used to measure RNA expression of key genes of lipid metabolism and normalised using Genorm (Table 1) ${ }^{(4)}$. AT lipid and protein concentration were assessed by Folch and Bradford assay, respectively. Haematoxylin and eosin staining of 5- $\mu$ m-thick AT sections were carried out and image analysis conducted to assess average adipocyte diameter. Statistical analysis was carried out using SPSS 17; all results are shown in Table 1.
\end{abstract}

Table 1. Summary of results VD, vaginal delivery; CS, pre-labour caesarean section; 11ßHSD1, 11ßhydroxysteroid dehydrogenase type 1 ; $11 \beta$ HSD2, $11 \beta$ hydroxysteroid dehydrogenase type 2; GR, glucocorticoid receptor; LPL, lipoprotein lipase; FABP4, fatty acid binding protein 4; FAS, fatty acid synthase

\begin{tabular}{|c|c|c|c|}
\hline & VD & CS & $P$ \\
\hline TAG content $(\mathrm{mg} / \mathrm{g})$ & $30.07 \pm 7.02$ & $20.16 \pm 7.93$ & 0.20 \\
\hline Protein concentration $(\mathrm{mg} / \mathrm{g})$ & $277.5 \pm 33.3$ & $129.6 \pm 20.1$ & 0.03 \\
\hline $11 \beta \operatorname{HSD} 1\left(2^{-\Delta \Delta^{\mathrm{CT}}}\right)$ & $1.28 \pm 0.24$ & $0.67 \pm 0.05$ & 0.01 \\
\hline $11 \beta \operatorname{HSD} 2\left(2^{-\Delta \Delta^{\mathrm{CT}}}\right)$ & $0.14 \pm 0.012$ & $0.11 \pm 0.01$ & 0.19 \\
\hline $\operatorname{GR}\left(2^{-\Delta \Lambda^{\mathrm{cT}}}\right)$ & $0.67 \pm 0.032$ & $0.48 \pm 0.05$ & 0.05 \\
\hline $\operatorname{LPL}\left(2^{-\Delta \Delta^{\mathrm{CT}}}\right)$ & $128.69 \pm 46.27$ & $116.79 \pm 35.22$ & 1.0 \\
\hline FABP4 $\left(2^{-\Delta \Delta^{\mathrm{CT}}}\right)$ & $250.28 \pm 77.04$ & $242.37 \pm 74.13$ & 0.67 \\
\hline FAS $\left(2^{-\Delta \Delta^{\mathrm{CT}}}\right)$ & $34.93 \pm 14.53$ & $36.48 \pm 7.91$ & 0.39 \\
\hline Average adipocyte diameter $(\mu \mathrm{M})$ & $1303.5 \pm 581.88$ & $271.2 \pm 113$ & 0.10 \\
\hline
\end{tabular}

Lipid accumulation does not appear to be affected by CS in these enterally fed animals. However, AT development may be impaired, as demonstrated by significantly lower expression of 11ßHSD1, GR expression and protein concentration combined with a trend towards reduced adipocyte diameter. These findings suggest a reduced sensitivity to glucocorticoids at an AT level that may have a long-term impact on ability to store and metabolise lipids. Further studies of parenterally fed CS and VD offspring may provide useful additional data.

1. Leone TA \& Finer NN (2006) Foetal adaptation at birth. Curr Paediatr 16(6), 373-378.

2. Cardwell C, Stene L, Joner G et al. (2008) Caesarean section is associated with an increased risk of childhood-onset type 1 diabetes mellitus: a metaanalysis of observational studies. Diabetologia 51(5), 726-735.

3. Hyde MJ, Griffin JL, Herrera E et al. (2009) Delivery by Caesarean section, rather than vaginal delivery, promotes hepatic steatosis in piglets. Clin Sci 118(1), 47-59.

4. Vandesompele J, De Preter K, Pattyn F et al. (2002) Acurate normalization of real-time quantitative RT-PCR data by geometric averaging of multiple internal control genes. Genome Biol 18(3), 1-12. 